\title{
What Sri Lankan Newspapers publish on Sexual Health? A content analysis
}

\author{
P.A.D.M.P Perera, D.L.D.C Liyanage, W.S Pannala, L.P.P. Godakandaarachchi, K.A.M. Ariyaratne
}

\begin{abstract}
Introduction: Sexual health is a taboo subject in the conservative Sri Lankan society. The reported number of HIV cases has doubled during last 6 years. With the high literacy rate, newspapers could be utilized as an effective media for sexual health promotion. Objective of this study is to analyse the quantity and content of sexual health related material published in newspapers.

Methods: This was a descriptive cross sectional study carried out using all available Sinhalese and English newspapers in the Public Library, Colombo within a randomly selected month in the year 2015. Newspapers were scrutinized to identify sexual health related articles and advertisements. Data collected using pre-tested checklists, independently by two researches. Data was analyzed using SPSS.

Results: Among a total of 236 newspapers, 210 articles and advertisements were on sexual health. Majority $(60 \%)$ were advertisements which appeared more in weekly Sinhala newspapers. Out of all advertisements $71 \%$ were on treatment services for sexual dysfunctions. $90 \%$ of advertisements did not indicate a service provider. None were on condoms. Nearly $50 \%$ of 85 detailed articles were related to risk populations, out of that $69 \%$ mentioned stigma/ discrimination. Only $1 / 3$ of articles directly mentioned STI, HIV or both. Two articles mentioned condoms as a preventive method and another 4 had details on linked to care.

Conclusions: There were many advertisements related to sexual health and most of them were advertising treatment services for sexual dysfunctions. Significant percentage of advertisements lacked details of the service provider. Very few articles addressed STD/HIV in-depth and they also markedly lacked information on condoms, link to care services including NSACP. The bulk of the analyzed articles were on at risk populations with mentioning of stigma/discrimination.
\end{abstract}

Key words: Sri Lanka, Newspapers, Sexual Health, Advertisement, Content analysis

\footnotetext{
Authors: Corresponding author: Dr P.A.D.M.P Perera, MBBS, PgD Ven, Registrar in Venereology, Postgraduate Institute of Medicine, University of Colombo, Sri Lanka, Email: piyumipp@gmail.com.

Dr D.L.D.C. Liyanage, MBBS, PgD Ven, Postgraduate Institute of Medicine, University of Colombo, Sri Lanka

Dr W.S. Pannala, MBBS, PgD Ven, Postgraduate Institute of Medicine, University of Colombo, Sri Lanka

Dr L.P.P. Godakandaarachchi MBBS, PgD Ven, Postgraduate Institute of Medicine, University of Colombo, Sri Lanka

Dr K.A.M. Ariyaratne MBBS, MSC, MD, Consultant Venereologist and coordinator strategic information management, National STD/AIDS Control Programme, No 29, De Saram Place, Colombo 10, Sri Lanka,

Acknowledgement: Chief librarian and the staff of the Public Library, Colombo, Sri Lanka

Conflict of interest: No conflict of interest

Funding: No special funding granted for this

Originality, previous publications or presentations: This was presented at $20^{\text {th }}$ Annual Scientific Sessions of the Sri Lanka College of Venereologists, and was awarded best oral presentation at the free paper session.

Submitted: 25.11.2015, Accepted: 12.12.2015
} 


\section{Full article}

\section{Introduction}

Sexual health including Sexually Transmitted Diseases (STDs) and HIV are taboo subjects in the conservative Sri Lankan society. Even though the prevalence of them is low, a rising trend is observed, especially the viral STDs. Though the HIV epidemic is classified as low level, the reported number of cases have doubled during last 6 years and a slow but a steady increasing trend among HIV infected young persons (15-24 years) is reported since 2003 (1). STDs are a newsworthy topic because they affect a large number of people, represent a significant health risk, are largely preventable, and disproportionately affect younger people (2). In Sri Lanka, the literacy rate is high and number of newspapers in circulation per 1000 is 94 non-daily newspapers and 38 daily newspapers, with a total number of 140 registered daily and weekly newspapers in all three languages (3), catering to all the nationalities in Sri Lanka. There are several categories of newspapers. National newspapers are published daily, weekly or monthly and also there are newspapers targeting special categories such as women, youth and children. Some are related to religion, astronomy and finance as well.

Newspapers are a main mode of media where news and other important information are disseminated throughout the country. Even though the quantity is apparently high, the quality of the news or the information they contain are questionable in some instances. Specially, when the sexual health related topics are concerned, even the quantity of them is doubtful as these issues are not discussed openly in this conservative society.

The news in papers is a major source of health information for the general population and health professionals as well. Unfortunately, this information is often superficial, confusing, or inaccurate and leads to the conclusion that, "the public is poorly served by the coverage of medical science in the general press" (2).
But with the rising trends of HIV and STDs, especially among the young age group of 15 to 24 years, increasing awareness is becoming more and more important. Areas such as the modes of transmission, risk factors and the importance of screening and the available services should be discussed more openly. Even though the HIV epidemic is low in Sri Lanka and the general population is not considered as most at risk, it is always important to increase awareness among all the strata of the society, so we can halt the progression of the epidemic. With its high coverage and circulation, newspapers can be utilized to achieve these purposes of public health. Therefore, the general objective of this study was to analyse the sexual health related newspaper articles and advertisements in relation to their quantity and content.

\section{Methods}

This was a descriptive cross sectional study carried out using all available Sinhalese and English newspapers in the Public Library, Colombo within a randomly selected month in the year 2015. Month of July was thus selected. The study sample consisted of all the related articles and advertisements published in all Sinhalese and English weekly/ weekend newspapers in July 2015 and another set of all daily newspapers of 10 randomly selected days. Any article which contained at least one sentence related to sexual health and any advertisement which contained at least one word related to sexual health was included in the study. A pre tested checklist was used as the study instrument and it was developed in English and was designed in consultation with a Consultant Venereologist. Questions regarding the type of article or advertisement, type of the author and the presence of a service provider and contents of the articles or advertisement were included in the check list. It was pre tested by two independent post graduate trainees in v Venereology, who were working more than two years in the field and not involved in this study to determine 
the acceptability, completeness, clarity and appropriateness of the check list. Based on the experience gained from the pre-test, necessary modifications were done in consultation with the Consultant Venereologist. Two investigators independently went through the selected articles and the advertisements and relevant data was extracted using the checklist. Any discrepancy between two investigators regarding controversial issues was discussed with other investigators and came to a conclusion. Data was entered to the computer using the Epidata software and analysis was done using SPSS.

\section{Results}

A total number of 236 newspapers were scrutinized which consisted of 128 weekly/ weekend newspapers and 108 daily newspapers. There were 171 Sinhalese and 65 English newspapers. A total number of 210 sexual health related articles and advertisements were found from these newspapers. Several types of articles were identified and among them majority $(n=125$, $60 \%$ ) were advertisements related to sexual health.

(In this; advertisement is also taken as an article)

Figure 1: Type of articles $(n=210)$

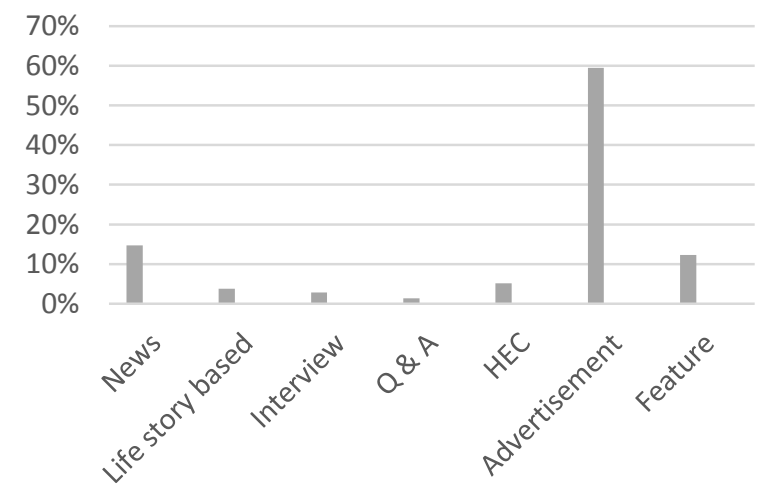

Sexual Health Related Advertisements

About $98 \%$ of the advertisements appeared in Sinhalese newspapers and $86.4 \%$ in weekly/ weekend newspapers. They were about treatment services and products related to sexual health and majority of the treatment services related advertisements (71.2\%) advertised regarding treatment services for sexual dysfunctions and the rest were on STD treatment. Advertisements regarding products were related to enhancing sexual pleasure. None of the advertisements were regarding condoms in this study sample. Among the advertisements only a $12 \%$ mentioned a service provider with or without their qualifications.

\section{Sexual Health Related Articles}

There were 85 detailed articles related to sexual health in this study population and majority (42\%) were related to key populations.

Table 1: Content type of articles $(n=85)$

\begin{tabular}{lr}
\hline \multicolumn{1}{c}{ Content type } & Frequency \\
\hline STD related & 9 \\
\hline HIV related & 7 \\
\hline Sexual dysfunctions related & 1 \\
\hline STD and HIV related & 6 \\
\hline Key population related & 36 \\
\hline Key population, STD and HIV related & 6 \\
\hline $\begin{array}{l}\text { Other (prevention of sexual or child } \\
\text { abuse) }\end{array}$ & 20 \\
\hline
\end{tabular}

It was interesting to note that almost $93 \%$ of these articles were written by non-medical personnel and among them $61 \%$ did not contain at least a resource. Less than $5 \%$ of the articles were written by MBBS qualified persons.

Majority (48\%) of the articles related to key populations were news articles.

Table 2: Type of articles related to key populations $(n=42)$

\begin{tabular}{lr}
\hline Type & Percentage \\
\hline News & $48 \%$ \\
\hline Feature & $24 \%$ \\
\hline Life story based & $14 \%$ \\
\hline Interview & $12 \%$ \\
\hline Health education column & $2 \%$ \\
\hline
\end{tabular}


In most of these articles (69\%) stigma and discrimination was mentioned.

Only 28 articles discussed in-depth and technical details of STD and HIV and they consisted of 9 features, 7 news, 5 health education columns, 4 interviews and 3 question and answer sections. The location and presentation of these articles were remarkable as $55.3 \%$ were placed in the main newspaper and more than $60 \%$ were the size of a half page or more. Colours and pictures were included in $67 \%$ and $84 \%$ of articles respectively.

Table 3: Type of topics frequently found on sexual health in the month of July 2015 $(n=28)$

\begin{tabular}{|c|c|c|c|c|}
\hline News (7) & Interviews (4) & $Q \& A(3)$ & $\begin{array}{l}\text { Health } \\
\text { education } \\
\text { columns } \\
\text { (5) }\end{array}$ & $\begin{array}{c}\text { Features } \\
\text { (9) }\end{array}$ \\
\hline $\begin{array}{l}\text { EMTCT of } \\
\text { HIV \& } \\
\text { Congenital } \\
\text { syphilis in } \\
\text { Cuba (X3) }\end{array}$ & $\begin{array}{l}\text { With } \\
\text { transgender } \\
(X 3)\end{array}$ & $\begin{array}{l}\text { Vaginal } \\
\text { discharg } \\
e(X 2)\end{array}$ & $\begin{array}{l}\text { Prevent } \\
\text { Hepatitis } \\
\text { (X3) }\end{array}$ & $\begin{array}{l}\text { Increasing } \\
\text { trend of } \\
\text { HIV } \\
\text { among } \\
\text { school } \\
\text { youth (X4) }\end{array}$ \\
\hline $\begin{array}{l}\text { Elimination } \\
\text { of HIV in } \\
2030\end{array}$ & $\begin{array}{l}\text { Candidiasis } \\
\text { With a } \\
\text { consultant } \\
\text { Venereologist }\end{array}$ & $\begin{array}{l}\text { Cervical } \\
\text { cancer } \\
\text { awarene } \\
\text { ss }\end{array}$ & $\begin{array}{l}\text { Vaginal } \\
\text { itching } \\
\text { and } \\
\text { discharge }\end{array}$ & $\begin{array}{l}\text { Preventio } \\
n \text { of } \\
\text { Hepatitis } \\
(X 2)\end{array}$ \\
\hline $\begin{array}{l}\text { HIV/Hepati } \\
\text { tis risk in } \\
\text { Sydney } \\
\text { dental } \\
\text { patients }\end{array}$ & & & $\begin{array}{l}\text { STD risk } \\
\text { from FSW }\end{array}$ & $\begin{array}{l}\text { Tourism } \\
\text { and sex } \\
\text { industry }\end{array}$ \\
\hline $\begin{array}{l}\text { HIV and } \\
\text { blood } \\
\text { safety }\end{array}$ & & & & $\begin{array}{l}\text { School } \\
\text { boy } \\
\text { finding } \\
\text { treatment } \\
\text { for HIV }\end{array}$ \\
\hline $\begin{array}{l}\text { STD/HIV- } \\
\text { NSACP } \\
\text { Annual } \\
\text { report }\end{array}$ & & & & $\begin{array}{l}\text { FSW and } \\
\text { their } \\
\text { issues } \\
\text { including } \\
\text { STI/HIV }\end{array}$ \\
\hline
\end{tabular}

Further analysis of the content was done to identify the presence of information in relation to epidemiology, risk behaviours, clinical presentations, management, prevention, condoms, link to care services, NSACP and stigma or discrimination.
Figure 2: Content analysis of STD \& HIV related articles $(n=28)$

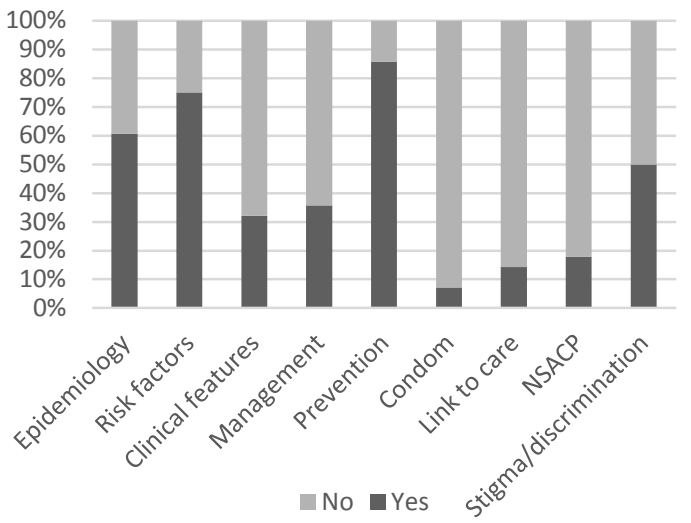

Majority of these articles mentioned about epidemiology, risk behaviours, prevention and $50 \%$ of them mentioned stigma/ discrimination. Only 2 articles mentioned condoms, and link to care services and NSACP was mentioned in less than 5 articles.

\section{Discussion}

Most of the sexual health related topics were in advertisements. They were more in Sinhalese, weekly/weekend newspapers and advertised mostly on treatment services where a service provider was not mentioned. After analysing the details of the advertisements used for the treatment services, the question which arose was whether they were placed by quacks as the service provider or their qualifications was not mentioned in majority of them.

None of the advertisements were for condoms in this study sample which is important to note as one of the ways to promote safe sex is correct and consistent use of condoms.

Sexual health related articles were given due prominence with placement and the presentation to attract the readers. Majority of the articles related to sexual health were written by non-medical personnel and did not contain a resource. Very few articles were written by qualified persons of this field. Therefore, the credibility of these articles was questionable. 
A content analysis of STDs in print news media was conducted in USA in 2004 showed a lack of substantive reporting on STDs in the print news media. This was demonstrated by the fact that only $19 \%$ of articles in the total sample mentioned the causes, consequences, prevention, signs, or symptoms, screening, transmission, treatment, trends or rates of STDs (2). In this study sample also a similarity was noted as only 28 articles had detailed information on STD or HIV and those too lacked sufficient information on important aspects such as symptoms and signs, prevention by condoms, testing and link to care services.

Mail \& Gardian did another content analysis and examined HIV/AIDS in headlines and lead paragraphs in a major South African newspaper, between June 1998 and May 2002 (4). It is interesting to note that there were very few articles that covered the population groups that have traditionally been associated with HIV/AIDS such as sex workers, homosexuals, drug users, and more recently prison inmates (4). Compared to this, in our content analysis, $42 \%$ of the detailed articles directly were on key populations and another $7 \%$ mentioned them in the context of STD and HIV. There were several interviews with transgenders in this study sample, which can be considered as a good strategy to increase awareness and to reduce stigma.

HIV/ AIDS: 25 years of press coverage, summarizes the findings of three studies that tracked press coverage of the disease in the United States, Southern Africa and Papua New Guinea from the 1980s. After 25 years of coverage, the five most dominant stories included, HIV prevention and protection $(18 \%)$, research $(13 \%)$, transmission $(13 \%)$, and social issues such as discrimination and stigma (10\%) according to this study (5). In our study sample, the most discussed topics were prevention (but condoms were not mentioned), risk behaviours and stigma and discrimination.
One of the limitations of this study was that Tamil newspapers were not included due to poor resources. Newspapers which were not available at the Public Library was not included. Qualitative assessment of stigma in the articles could not be done due to time limitations.

\section{Conclusions}

As advertisements on treatment services were not mentioning a service provider, quacks placing these advertisements could have been a high possibility.

As most of the articles related to sexual health were written by non-medical personnel and majority has not taken the trouble to at least quote a resource, the credibility of these articles were also questionable.

Even though these articles were given due prominence to increase curiosity of the reader, the content was unsatisfactory as they lacked information on many important areas related to sexual health such as symptoms and signs of STD and HIV, prevention by condoms, testing and link to care services including NSACP and peripheral STD clinics. Therefore, as a country, planning to "close the gap" and send the message "test today" across the island, it is doubtful as to the use of newspapers in this regard.

Sri Lanka is targeting elimination of mother to child transmission of HIV and congenital syphilis and in relation to sexual health, this is a very important aspect which the general public should be aware, as the intervention is targeted at the antenatal clinics. But such issues were not discussed in this study sample in relation to Sri Lanka.

Another current issue like the rising trend of viral STDs was inadequately discussed, even though the knowledge about it would help to prevent STDs.

It was satisfying to note that articles on key populations were high in number and stigma 
and discrimination was also mentioned in most of them.

Even though health education columns are the type of articles which can be used directly to increase awareness of STD and HIV by providing in depth and quality technical details, they were underutilized in this study sample.

\section{Recommendations}

When advertisements are taken as a proxy for the people who are searching for sexual health related material, we can assume that they will be reading Sinhalese weekly/ weekend newspapers more, as the majority of advertisements are placed in them. Therefore, the best newspaper type to use as a medium to deliver regarding sexual health is Sinhalese weekly/weekend newspapers to catch the target population.

It is important to conduct awareness programmes for journalists regarding the important aspects of sexual health coverage, thereby increasing the quality of the articles and utilize them to get the correct message delivered to the public.

As noted, there is a need to write more articles by professional and qualified persons, about current topics which are important to Sri Lanka. It is also important to write articles of available testing and care services in detail.

\section{References}

1. Strategic Information Management unit, NSACP. Annual report 2014. Sri Lanka: National STD/AIDS Control Programme, Ministry of Health; 2014. 148p

2. Davidson A.E, Wallack L (2004) A Content Analysis of Sexually Transmitted Diseases in the Print News Media, Journal of Health Communication: International Perspectives, 9:2, 111-117, DOI: 10.1080/10810730490425268

3. Department of National Archives. Newspapers published in Sri Lanka (Corrected up to December 31, 2013). Sri Lanka: Department of National Archives: 2014.

4. Visser M, Hsu C.Y, Kalinskaya S, The story behind the headlines: HIV/AIDS in a leading South African newspaper, working paper, 2003, http://learndev.org/dl/StoryBehindHeadlines.pdf.

5. Cullen T, "HIV/AIDS: 20 years of press coverage," Australian Studies in Journalism, 2003, 12: 64-82 